\title{
Chromium Electroplating of Aluminium Alloys Using Electroless Nickel as Underlayer
}

\author{
Chike F. Oduoza*, Enam Khan, Tarsem Sihra \\ Faculty Science and Engineering, University of Wolverhampton, City Campus, Wolverhampton, UK \\ Email: ${ }^{*}$ C.F.Oduoza@wlv.ac.uk
}

Received 26 May 2014; revised 25 June 2014; accepted 24 July 2014

Copyright (C) 2014 by authors and Scientific Research Publishing Inc.

This work is licensed under the Creative Commons Attribution International License (CC BY). http://creativecommons.org/licenses/by/4.0/

(c) (i) Open Access

\begin{abstract}
The growing demand for chromium coated aluminium components especially for the automotive industry is due to their favourable physical properties (density, strength to weight ratio etc.). However, their frequent use under harsh environmental conditions renders them corrosion sensitive and consequently they need to be protected. An approach that has been applied in industry is to directly electroplate nickel onto aluminium substrate prior to a top metallic finish; however, in components with complex geometry, certain areas could become exposed to corrosion attack due to poor surface coverage during plating. In this study, a modified electroless nickel undercoat was applied to pre-treated aluminium alloys prior to duplex nickel and chromium plating with a view to enhance corrosion resistance, improve coating adherence and durability, and overall, to achieve substrate protection. Hexavalent and trivalent chromium were applied to pre-treated Al 1050 and Al 6061 following electroless nickel deposition, and plating performance was assessed by surface and corrosion techniques, while durability was measured by scratch, adhesion and hardness tests. Overall, while chromium plating with an electroless nickel undercoat did not improve corrosion resistance or hardness of the materials, it provided an additional protective layer for the substrate with a potential for longer term durability.
\end{abstract}

\section{Keywords}

Aluminium Alloys, Electroless Nickel, Chromium Plating, Corrosion Testing, Scratch and Hardness Testing

\section{Introduction}

The increasing need to achieve fuel economy, triggered by environmental concerns and increasing energy prices,

${ }^{*}$ Corresponding author.

How to cite this paper: Oduoza, C.F., Khan, E. and Sihra, T. (2014) Chromium Electroplating of Aluminium Alloys Using Electroless Nickel as Underlayer. Journal of Materials Science and Chemical Engineering, 2, 59-74.

http://dx.doi.org/10.4236/msce.2014.27007 
has significantly influenced material selection during manufacture. The use of lightweight materials can help reduce vehicle weight and improve fuel economy. The weight reduction concept has driven a gradual decrease in the use of ferrous metals and the corresponding increase in the use of lightweight materials such as aluminium in the automotive industry. Manufacturers especially in the aerospace, architectural, automotive, packaging and the construction industries have gradually shifted towards the use of light alloys such as aluminium, magnesium and titanium [1] [2]. However, the poor surface characteristics of light metals have limited successfully protective coating of the substrates. Therefore, they cannot meet the requirements for durability and functionality in applications, where they are exposed to wear, corrosion and friction unless adequate surface modifications or coating is provided

The aim of this study is to apply an electroless undercoat to pretreated aluminium alloys prior to a surface metallic finish with duplex nickel and chromium, in order to improve corrosion resistance of the substrate. Variants of hexavalent and trivalent chromium plating will be applied to pre-treated $\mathrm{Al} 1050$ and $\mathrm{Al} 6061$ following electroless nickel deposition and then characterised by surface analysis techniques. The chromium finish would also be tested for scratch adhesion, hardness and corrosion resistance.

The satisfactory provision of decorative and functional surfaces on light metals such as aluminium depends critically on the preparation of the substrate for electrodeposition [3] [4]. Electrodeposition onto aluminium poses a number of fundamental problems to the electroplater. Aluminium has great affinity for oxygen and when it is exposed to air, direct oxidation causes the spontaneous formation of a thin, compact, tough and inert film of oxide. Therefore, special pretreatment sequences are essential in order to enable aluminium substrates to be electroplated with adherent coatings. Without a full appreciation of the alloy composition and the level of heat treatment that it has been subjected to, it may be difficult to select an appropriate pretreatment sequence. A series of pretreatment procedures for aluminium and its alloys have evolved aimed at improving the levels of adhesion between aluminium and the plated metal. Immersion film, based on zincate solutions, is the most widely used technique prior to electrodeposition of metallic coatings on aluminium [3].

Pretreatment of aluminium prior to electroplating, generally involves cleaning, etching, desmutting and zincating. Alkaline process solutions are effective in removing oxides from aluminium surface, because aluminium oxide is more soluble in alkali than in acid. The most common pretreatment method currently used is to directly electroplate nickel onto the aluminium substrate. However, nickel electroplating can lead to problems due to unsatisfactory deposits in low current density areas (complex geometry).

Since aluminium is less noble than chromium in the passive state, there is a risk of an accelerated corrosion of the aluminium substrate plated with a thin decorative deposit of chromium without a prevailing intermediate layer. Hence an under layer of copper or nickel or both would need to be applied on aluminium (in pure or alloy form) before chromium coating [5]. Takacs et al. [6] studied the effects of pre-treatment on the corrosion properties of electroless Ni-P layers deposited on AlMg2 alloy. Using a measure of polarisation resistances, they found that the nickel pre-coating and the hypophosphite adlayer formed by suitable immersion pre-treatments improved the corrosion resistance of the samples immersed in aerated sodium sulphate solution. They attributed the decrease in corrosion resistance to the lower micro porosity and smoother morphology of the nickel-phosphorus coatings. In another study, Hino et al. [7], researched on the effects of zincate treatment on adhesion of electroless Ni-P coating on various aluminium alloys. They concluded that initial zinc deposition on the surface is an important factor influencing the morphology of the second zincate deposit and its adhesion.

The plating industry also faces a problem with chromium plating of aluminium in the light of legislation restricting the use of hexavalent chromium in the plating industry. Voorwald et al. [8] studied the effect of electroless nickel interlayer on the fatigue strength of chromium electroplated AISI 4340 steel. They concluded that the hard chromium electroplating showed excellent adhesion when applied on steel, as well as on the electroless nickel plating. It was also established that the nickel interlayer was able to inhibit or retain the propagation of many original cracks from the hard chromium external layer to the substrate. Hamid and Elkhair [9] have developed electroless nickel-phosphorus composite deposits for wear resistance of $\mathrm{Al} 6061$ while Wu, Zhao, Xie and Yang [10] have reviewed electroplating and electroless plating on Magnesium alloys. Khan et al. [11] reviewed regulatory, technical and economic issues involved in replacing hexavalent chromium plating as stringent restriction legislations have been introduced to phase out hexavalent chromium or limit its use in the plating industry. A promising alternative to hexavalent chromium plating [12] is trivalent chromium plating.

Figure 1 shows samples of failed electro and electroless nickel depositions as a result of inadequate pretreatment of the aluminium alloy substrate showing blisters, delamination and detached deposition. 

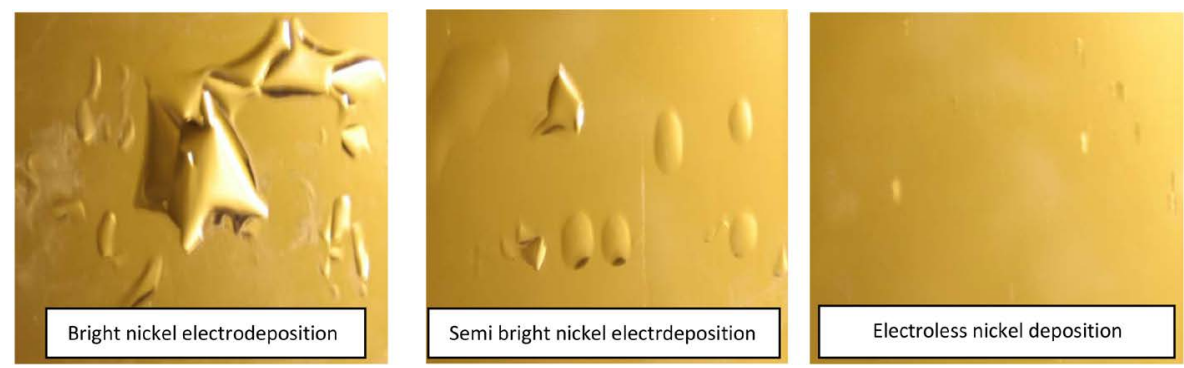

Figure 1. Failed nickel deposition on pretreated Aluminium Alloys [13] 1000× magnification.

\section{Experimental Procedure}

Aluminium alloys consisting of $\mathrm{Al} 1050$ and $\mathrm{Al} 6061$ were samples used in this study for chromium plating involving; zincating, electroless nickel deposition, duplex nickel and chromium electroplating. Samples were guillotined to size with the following dimensions: $100 \mathrm{~mm} \times 100 \mathrm{~mm} \times 1 \mathrm{~mm}$ for both alloy samples. Chemical compositions of $\mathrm{Al} 1050$ and $\mathrm{Al} 6061$ have been presented and discussed in Aluminium Federation [14].

\subsection{Procedures for Sample Preparation/Plating}

Figure 2 shows the research methodology adopted for chromium electro plating of aluminium alloys. The process starts with pretreatment of samples using the zincating process which involves cleaning, etching, desmutting and zincating. The zincate removes oxide layer and minimises re-oxidation of sample surface before duplex nickel and chromium are deposited onto the alloys. The operating conditions used were based on the Bondal process [15] for pretreatment of aluminium alloys as recommended by MacDermid, using Minco cleaner [16] and 66-Microetch [17].

The next stage after zincating involves plating nickel as an undercoat prior to chromium deposition. In this study the option of applying electroless nickel for nickel deposition on the substrate was considered which was deposited at the rate of 15 - 20 micron-hr using commercial solution VAND-ALOY 6000 [18], formulated in sodium hypophosphite as the reducing agent and other additives.

Semi bright nickel (maximum of $0.005 \%$ sulphur) deposited to a thickness of $60 \%-75 \%$ is generally used in combination with bright nickel to achieve a robust corrosion protection of the metal. The rationale for this approach is that bright nickel which is less noble than the semi bright nickel layer corrodes preferentially, and there by protects the substrate. Proprietary solutions NiMac SF`[19], NiMac Clarion II formula [20] were used for semi bright [17] and for bright nickel deposition, while NiMac Hypore XL [21] was used for microporous nickel deposition.

Finally, chromium plating is achieved by depositing 0.5 um of chromium over thin microporous nickel (nickel thickness of lum), thus preventing rapid local corrosion. This study was able to apply both hexavalent and trivalent chromium plating on the samples based on formulation by MacDermid Plc, while proprietary solution Mach II [22] was used for hexavalent chromium deposition, TriMac III [23] trivalent chromium was used for trivalent chromium plating. Overall, four variants for chromium plating were adopted as follows.

- Pretreatment/Duplex nickel/Microporous nickel/Hexavalent chromium

- Pretreatment/Duplex nickel/Microporous nickel/Trivalent chromium

- Pretreatment/Electroless nickel/Duplex nickel/Microporous nickel/Hexavalent chromium

- Pretreatment/Electroless nickel/Duplex nickel/Microporous nickel/Trivalent chromium

Details of procedures for plating electroless nickel, microporous nickel, semi bright nickel, bright nickel and chromium on to aluminium samples have been described by Khan [13]. TriMac III, a proprietary solution MacDermid [23] was used for trivalent chromium. The chemical composition and operating conditions of TriMacIII are as follows.

TriMac III conductivity salts

Total chromium metal

Temperature

$\mathrm{pH}$

Cathode current density

Voltage

Agitation

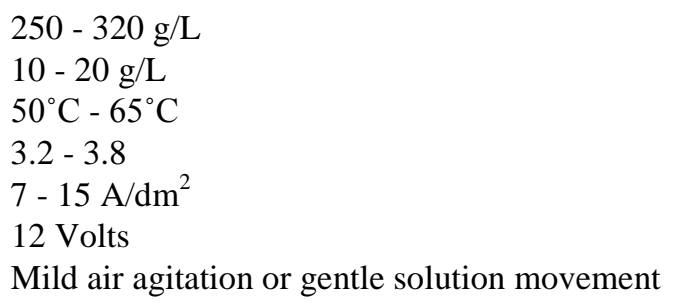



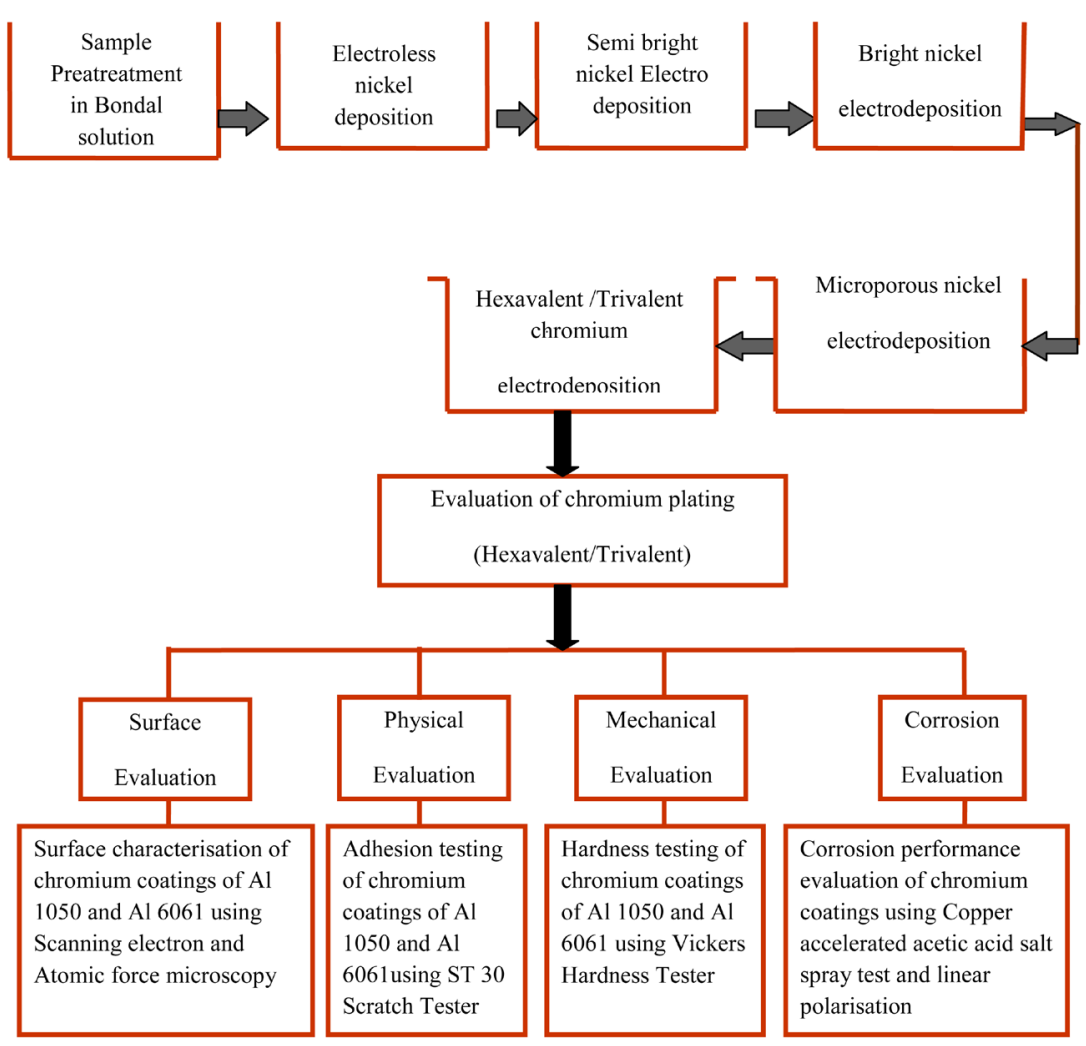

(a)

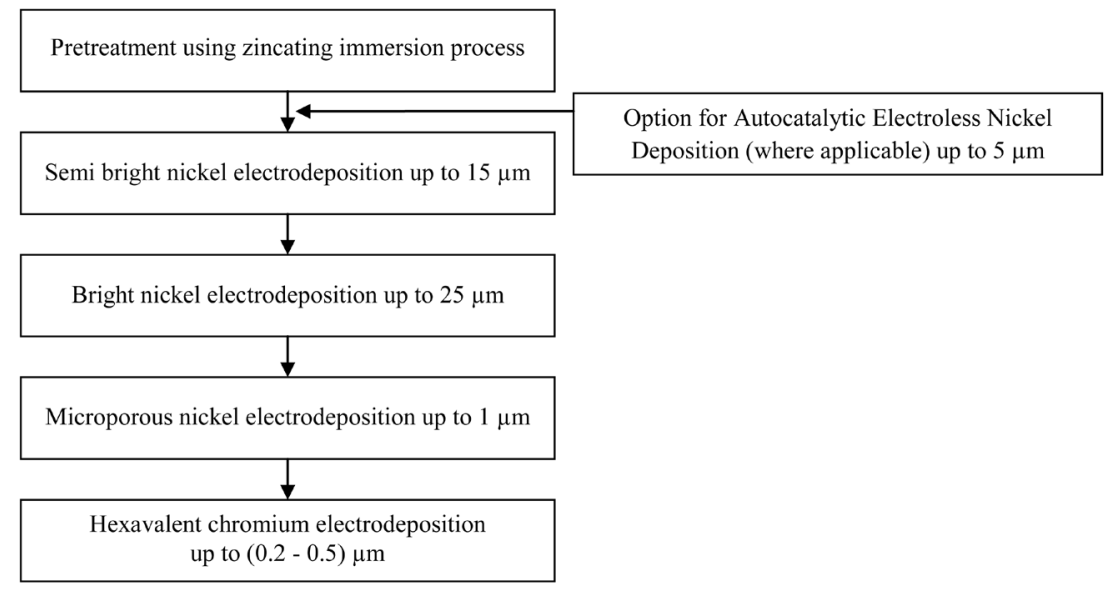

(b)

Figure 2. (a) Summary of Research Methodology for Chromium Plating of Aluminium Alloys; (b) Flow chart for duplex nickel/chromium coating of Al samples with the option of electroless nickel undercoat [13].

\subsection{Procedures for Sample Testing after Chromium Plating}

\subsubsection{Copper Accelerated Salt Spray Test (CASS)}

Corrosion testing of variant chromium plated $\mathrm{Al} 1050$ and $\mathrm{Al} 6061$ samples was carried out using copper accelerated acetic acid salt spray test (CASS). The copper accelerated acetic acid salt spray test was developed specifically to test nickel/chromium and copper/nickel/chromium electrodeposited coatings and it is also used to determine the corrosion resistance of various aluminium alloys [24]. The copper-accelerated acetic acid salt spray test (ASTM, B-368) is more rapid than the acetic acid salt spray test (ASTM, B287) and has been used in 
many automotive applications.

\subsubsection{Scanning Electron Microscopy (SEM)}

A ZEISS EVO scanning electron microscope 60 series interfaced with smart SEM software was used with a resolution of $3.0 \mathrm{~nm}$ at $0.2-30 \mathrm{KeV}$ acceleration voltage and a magnification of up to $5-1,000,000 \times$ with $3072 \times$ 2304 pixel images [25]. ZEISS EVO scanning electron microscope 60 series interfaced with smart SEM software was used to examine immersion deposit on $\mathrm{Al} 1050$ and $\mathrm{Al} 6061$ alloys cross sectional chrome plated samples and after 96 hours of CASS test. It has a resolution of $3.0 \mathrm{~nm}$ at $0.2-30 \mathrm{KeV}$ acceleration voltage. A magnification up to $5-1,000,000 \times$ with $3072 \times 2304$ pixel images could be achieved [26].

\subsubsection{Atomic Force Microscopy (AFM)}

The atomic force microscopy technique was carried out on four coatings on Al 1050 and Al 6061. The chromium electroplated samples were examined using the Thermo Microscope and MS Interface Module atomic force microscope. The most common statistical parameters obtained from atomic force microscopy were Ra (the average roughness deviation) and Rms (the root mean square roughness deviation) respectively. Ra and Rms values for the four different coatings onto $\mathrm{Al} 1050$ and $\mathrm{Al} 6061$ were calculated from topographical data using SPMLab 5.01 software. Atomic force microscopy produces images by recording interaction forces between the apex of probe tip and atoms present at the sample surface as the tip is scanned over the surface of the sample [27] [28].

\subsubsection{Linear Sweep Voltammetry}

A potentiostat (EG + G Instruments, Model 263A) with three electrode arrangement was used to determine the corrosion current density (Icorr) using linear polarization [29]. This was carried out in 5\% neutral sodium chloride solution using a $\mathrm{Ag} / \mathrm{AgCl}$ reference electrode over a potential range of $+/-20 \mathrm{mV}$ vs open circuit potential. The equilibrium time that the $1 \mathrm{~cm}^{2}$ surface of panel is in contact with the $\mathrm{NaCl}$, was varied between 30 and 60 minutes to record polarisation resistance of the chromium coated samples. The electrochemical corrosion test was carried out on chromium plated samples using linear polarization technique to derive the Icorr values.

\subsubsection{Scratch Adhesion Testing}

Adhesion test for variants of chromium deposits was carried out using the scratch tester ST 30 (with a diamond indentor, a cone angle of 120 degrees, tip radius of $0.2 \mathrm{~mm}$ and load range of $1.0-200.0 \mathrm{~N}$ ) designed to characterize the adhesive strength of coatings deposited on flat substrates (Stallard et al. [30]). The scratch tester enables measurement of the critical load at which a coating first shows signs of failure. Adhesion testing was carried out with single pass under progressive loading of $0-200 \mathrm{~N}$ with a scratch speed of $5.0-400 \mathrm{~mm} / \mathrm{minute}$. The indentor tip was drawn across the coatings with a loading rate of $100 \mathrm{~N} / \mathrm{mm}$ and a sliding speed of 10 $\mathrm{mm} / \mathrm{min}$. Measurement of the total length of the scratch and distance along the scratch at which the failure first occurs enables the critical load of the coating to be calculated recorded as the normal force at which the damage was first observed [31]. The lower critical load is defined as the load at which initial coating failure is detected, the upper critical load is that where significant damage is apparent and the coating is no longer suited for its intended use [32]. Figure 3 shows evidence of coating failure both at first and second critical loads.

\subsubsection{Vickers Hardness Testing}

Universal Vickers hardness testing on chromium deposits was carried out using Zwick Roell-Z20, 20 KN materials testing machine interfaced with X-pert software. The software monitors and controls hardness testing characteristics such as nominal force, travel speed range, mounting height, and calibration factors. Test loads, and indentation depth are used to calculate coating hardness (Zwick Roell Hardness testing). A defined load is applied through Vickers diamond indenter pressed into tested samples. Vickers Hardness Number (VHN), is obtained as the load divided by the surface area of the indentation. According to Chandler [33], Vickers Hardness Number $(V H N)$ is expressed as:

$$
V H N=1.854 P / L^{2}
$$

where " $P$ " is the applied force in $\mathrm{kg}$ and " $L$ " is the average length of diagonals. 
(a)

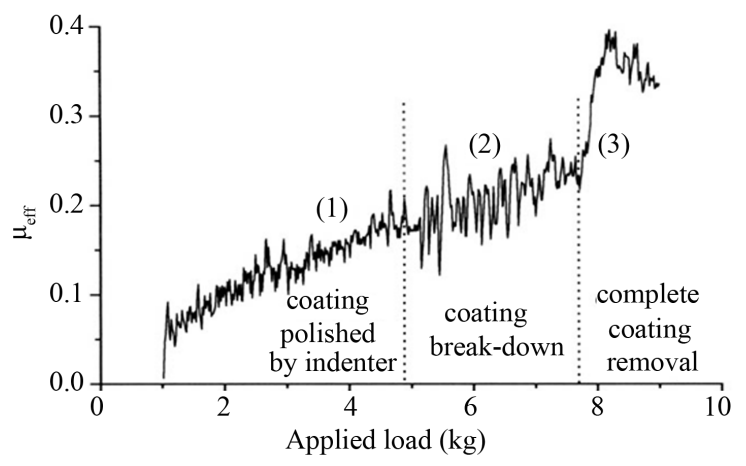

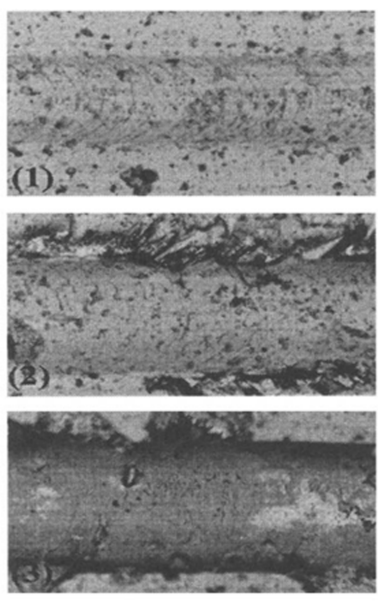

(b)

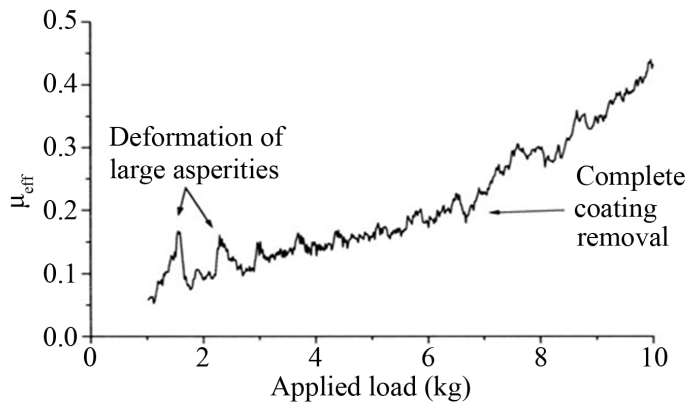

Figure 3. Evidence of coating failure through complete coating removal (Dryda and Sayer) [33].

\section{Results}

\subsection{Surface Characterization of Chromium Electroplated Al 1050 and Al 6061}

Atomic force microscopy was carried out on eight variant chromium coatings of $\mathrm{Al} 1050$ and $\mathrm{Al}$ 6061. Figure 4 and Figure 5 show sample micrographs obtained from scanning an area of $100 \mu \mathrm{m}$ by $100 \mu \mathrm{m}$ of chromium electroplated samples. Figure 4 clearly shows microcracks and minor inclusions on duplex nickel/hexavalent chromium deposited onto $\mathrm{Al} \mathrm{1050.} \mathrm{The} \mathrm{presence} \mathrm{of} \mathrm{microcracks} \mathrm{could} \mathrm{be} \mathrm{as} \mathrm{a} \mathrm{result} \mathrm{of} \mathrm{residual} \mathrm{tensile} \mathrm{stress}$ especially at thicknesses exceeding 0.8 microns. However, chromium deposition on $\mathrm{Al} 1050$ and $\mathrm{Al} 6061$ appear to have better surface characteristics compared to the over thirty microcracks per sq-mm observed on deposits from a hexavalent chromium electrolyte bath according to Dennis and Such [5] and Snyder [30].

Variant coatings of $\mathrm{Al} 1050$ and $\mathrm{Al} 6061$ were studied to quantify surface roughness using atomic force microscopy. Table 1 shows average roughness and root mean square roughness values (measured in nanometers) obtained from four variant chromium coatings on the samples. The average (Ra) value for duplex nickel/hexavalent chromium deposit on Al 1050 was $0.065 \mathrm{~nm}$, while the average $(\mathrm{Ra})$ value for duplex nickel/trivalent chromium deposits onto $\mathrm{Al} 1050$ was $0.092 \mathrm{~nm}$. The average roughness ( $\mathrm{Ra}$ ) value for duplex nickel/hexavalent chromium deposit on $\mathrm{Al} 6061$ was $0.036 \mathrm{~nm}$ compared to the trivalent which was $0.033 \mathrm{~nm}$. The root mean square roughness values calculated for $\mathrm{Al} 1050$ and $\mathrm{Al} 6061$ showed similar trends to the surface roughness. Overall, the conclusion from the study was that average roughness and root mean square roughness values were comparatively higher for Al 1050 than for Al 6061 while trivalent variants showed higher surface roughness compared to the hexavalent variants. The results also show that surface roughness may be influenced by the undercoat since roughness was lower in the variants with electroless nickel undercoat.

\subsection{Cross-Sectional Evaluation of Variant Chromium Coatings on Al 1050 and Al 6061}

The highly reflective nature of chromium deposits made it difficult to characterise plain view images of the 


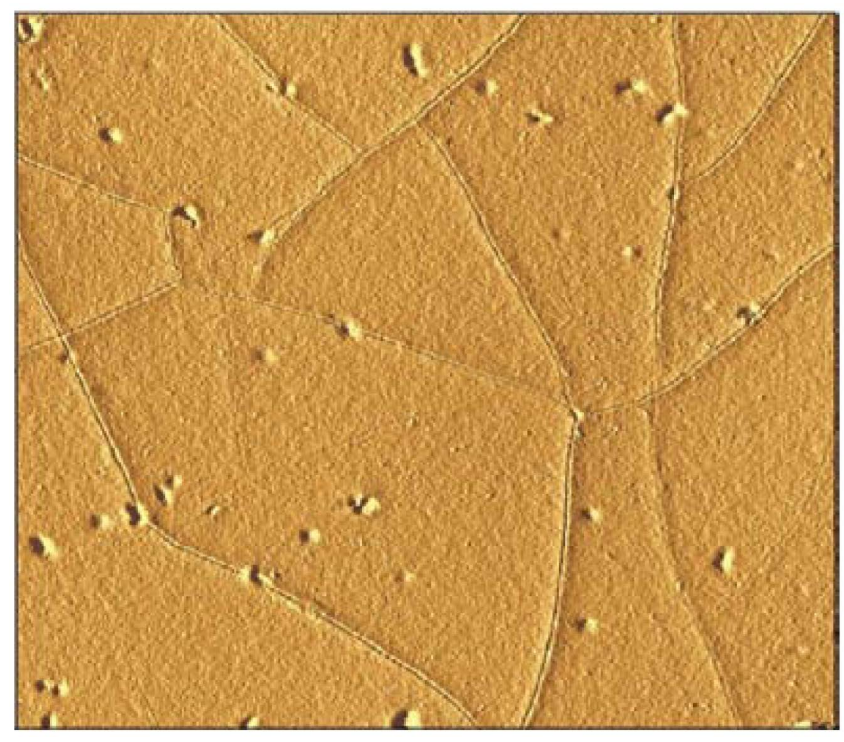

Figure 4. Atomic force microscopic image of duplex nickel/ hexavalent chromium (1 micron thick, ×2.5 K) for Al 1050 (Force volume scan $10,000 \mu \mathrm{m})$.

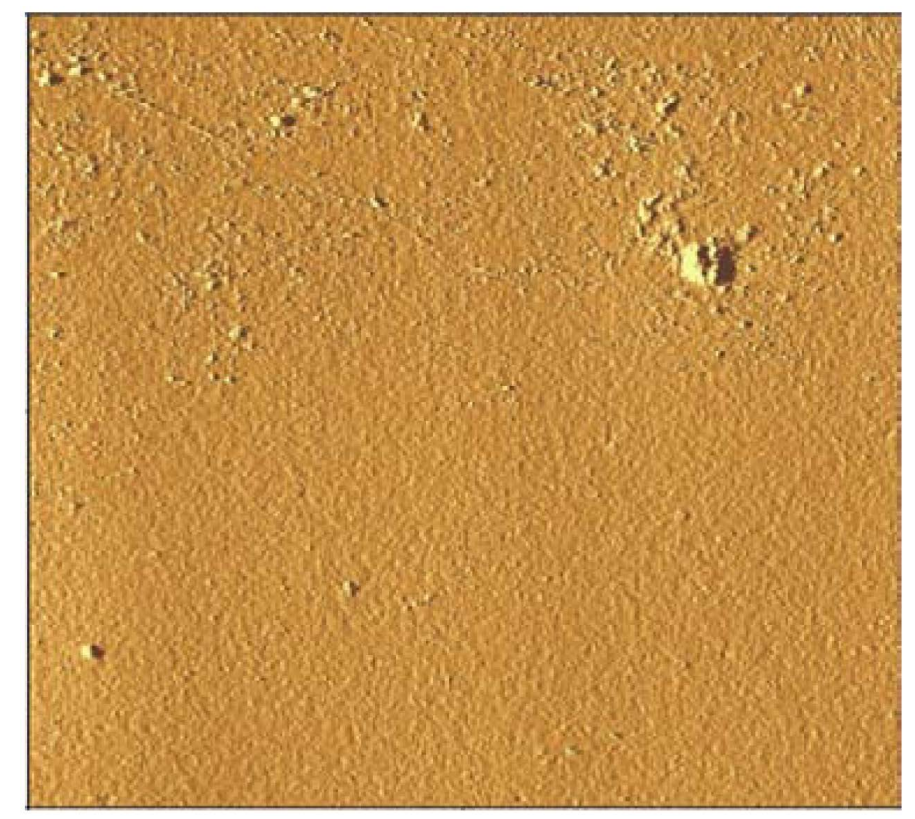

Figure 5. Atomic force microscopic image of duplex nickel/hex-avalent chromium ( 1 micron thick, $\times 2.5 \mathrm{~K}$ ) for $\mathrm{Al} 1050$ with electroless nickel undercoat (Force volume scan 10,000 $\mu \mathrm{m}$ ).

samples using atomic force microscopy. For instance it was difficult to identify pores, cracks, and the different layers of nickel and chromium from the deposits. Scanning electron microscopy technique therefore was used to view cross sections of chromium deposits on the samples. Figure 6(a) shows a cross section of duplex nick-

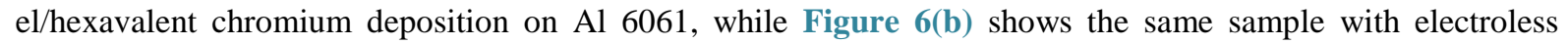
nickel undercoat. The figures show distinct layers highlighting the thicknesses of semi bright nickel and bright nickel measuring $25 \mu \mathrm{m}$ and $15 \mu \mathrm{m}$ respectively. Figure 7(a) and Figure 7(b) also show duplex nickel/trivalent chromium deposit and the variant with electroless nickel plating respectively measuring approximately $5 \mu \mathrm{m}$ thick. 


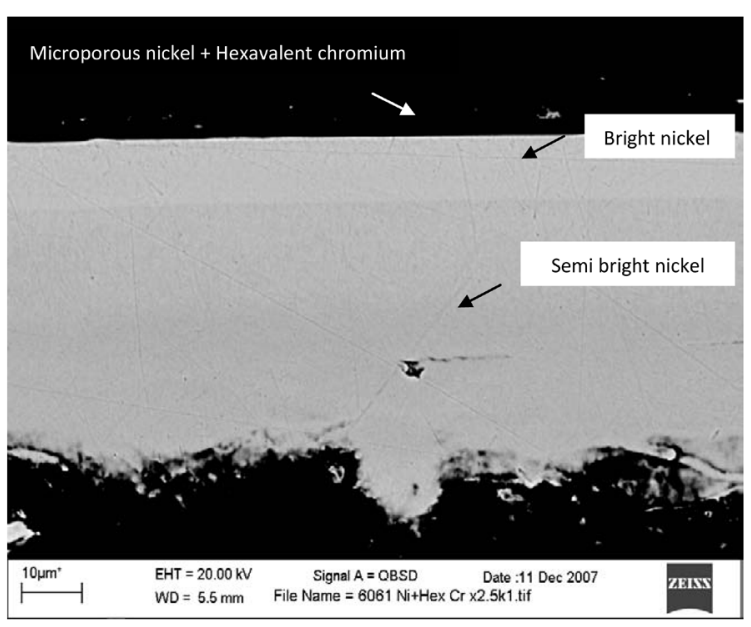

(a)

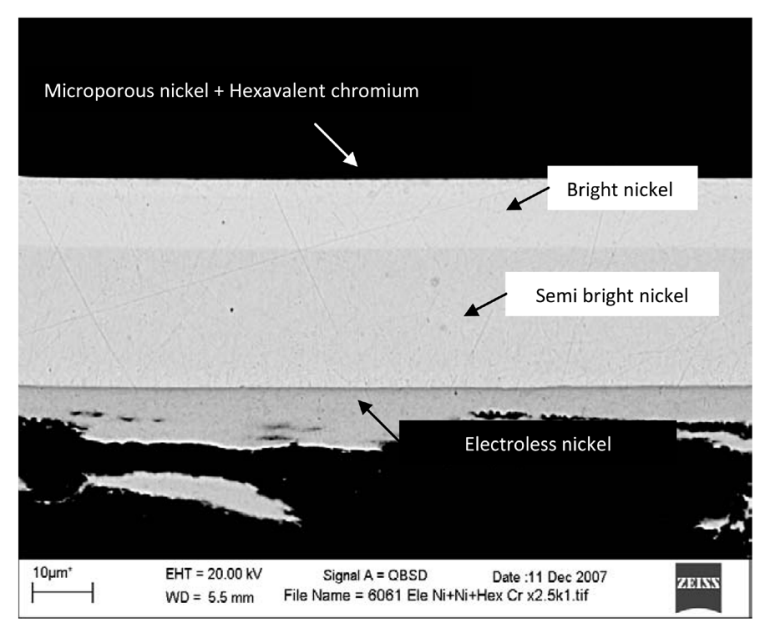

(b)

Figure 6. (a) SEM of cross section of duplex nickel/hexavalent chromium plated onto Al 6061; (b) SEM of cross section of duplex nickel/hexavalent chromium plated onto $\mathrm{Al} 6061$ with electroless nickel undercoat.

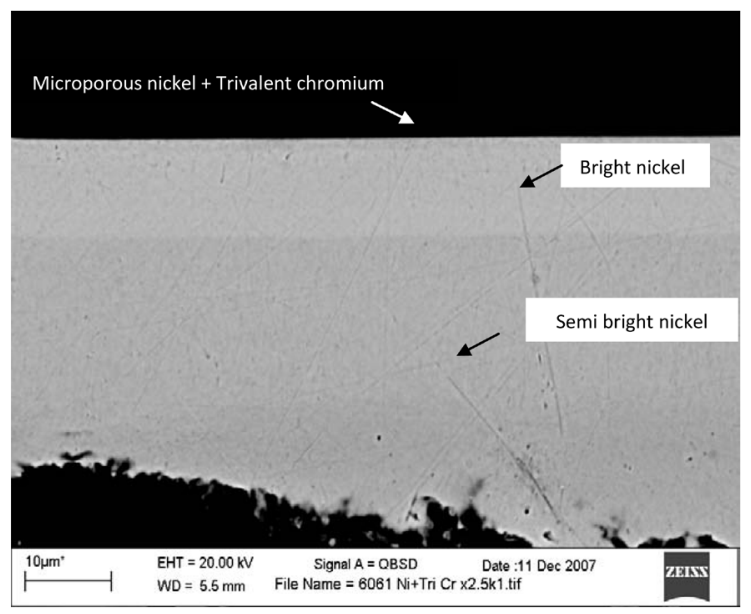

(a)

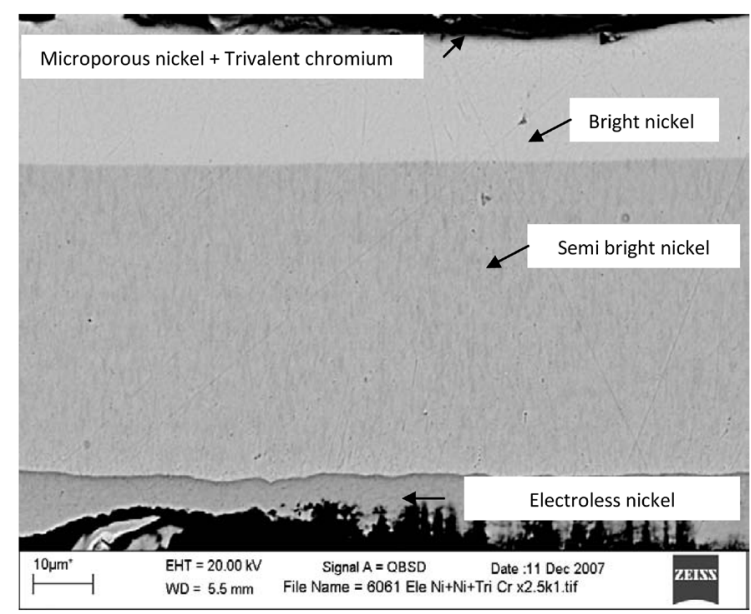

(b)

Figure 7. (a) SEM of cross section of duplex nickel/trivalent chromium plated onto Al 6061; (b) SEM of cross section of duplex nickel/trivalent chromium plated onto $\mathrm{Al} 6061$ with electroless nickel undercoat.

Table 1. Data for atomic force microscopy showing average and root mean square roughness values obtained for chromium plated $\mathrm{Al} 1050$ and $\mathrm{Al} 6061$.

\begin{tabular}{|c|c|c|}
\hline Aluminium Alloy Samples & Ra (nm) & RMS (nm) \\
\hline Duplex nickel + Chromium (Hexavalent) electrodeposition onto Al 1050 & 0.066 & 0.071 \\
\hline Duplex nickel + Chromium (Hexavalent) electrodeposition onto Al 1050 + electroless nickel undercoat & 0.058 & 0.068 \\
\hline Duplex nickel + Chromium (Trivalent) electrodeposition onto Al 1050 & 0.093 & 0.120 \\
\hline Duplex nickel + Chromium (Trivalent) electrodeposition onto Al 1050 + electroless nickel undercoat & 0.059 & 0.061 \\
\hline Duplex nickel + Chromium (Hexavalent) electrodeposition onto Al 6061 & 0.034 & 0.043 \\
\hline Duplex nickel + Chromium (Hexavalent) electrodeposition onto Al 6061 + electroless nickel undercoat & 0.031 & 0.039 \\
\hline Duplex nickel + Chromium (Trivalent) electrodeposition onto Al 6061 & 0.033 & 0.041 \\
\hline Duplex nickel + Chromium (Trivalent) electrodeposition onto Al 6061 + electroless undercoat & 0.032 & 0.040 \\
\hline
\end{tabular}




\subsection{Scratch Adhesion Testing of Variant Chromium Coatings on Al 1050 and Al 6061}

Scratch adhesion tests were carried out on variant chromium coatings on Al 1050 and Al 6061 samples to characterize the adhesive strength of coatings deposited. Figure 8(a) and Figure 8(b) show the graphs of frictional force, first derivative of frictional force and acoustic emission plotted on the $\mathrm{Y}$ axis against the applied load on the $\mathrm{X}$ axis for $\mathrm{Al} 1050$ without and with electroless nickel undercoat respectively. Adhesion of chromium coating was dependent on forces due to Van der waals', electrostatics and chemical bonding. Frictional force increased with load applied until the first critical load (Lc1) was reached when the first damage occurred at 85 $\mathrm{N}$ for duplex nickel/trivalent and the second critical load (Lc2) was reached at about $135 \mathrm{~N}$.

The scratch adhesion test is influenced by a number of intrinsic and extrinsic factors which are not adhesion related [34]. The stress developed around an indentor in scratch adhesion testing of a chromium coating is very complex and it is difficult to determine the stresses which caused the detachment of the coatings. The mechanism for scratch testing from SEM micrographs shows that buckling is developed at the head end of the crack followed by chipping which continues along the scratch channel. The high critical load obtained with duplex nickel/chromium coatings confirmed that damage occurred at a higher than normal load. Uniform and conformal shapes were observed across the scratch length after the scratch adhesion tests. This indicates that the coatings are capable of absorbing energy of the indentation due to their elastic/plastic behaviour. A mixture of concave and convex shapes are observed in the middle of the scratch, where the cracks seemed to be deeper. These results confirm that the coatings can not easily undergo delamination and flaking even at higher than normal loads.

Table 2 shows the first and second critical loads obtained from the scratch adhesion test. In all cases studied, Al 1050 showed higher first and second critical loads compared to Al 6061. It also appeared that trivalent coating was more adherent compared to the hexavalent coating.

The scratch test has been used to assess the adhesion of thin hard coatings and is a useful tool for coating development for quality assurance. Previous research confirms that the test is influenced by a number of intrinsic and extrinsic factors which are not adhesion-related and the results of the test are usually regarded as only semi-quantitative (Bull and Berasetegui, 2006) [33]. The stress state around a moving indenter scratching a coating/substrate system is thought to be very complex and therefore, it is difficult to determine the stresses which lead to coating detachment. It is thought that, the interfacial defect state responsible for failure is unknown, however, by careful analysis of failure modes in a scratch test (not all of which are related to adhesion) it is possible to identify adhesive failures.

Figure 9 shows the load depth profile for $5 \mathrm{~kg}$ force applied on Aluminium alloy 6061 plated with Duplex Nickel Hexavalent (Figure 9(a)) and Duplex Nickel Trivalent Chromium (Figure 9(b)) deposits. It shows the load on and off cycle (cycle of loading and unloading) and the depth of indentation left on the sample. The indentation depth is measured in two forms as maximum depth achieved at applied load as well as the depth of indentation after removing the load. A load of $5 \mathrm{~kg}$ force left an indentation depth of $32 \mu \mathrm{m}$ on the Duplex Hexavalent chromium variant compared to $35 \mu \mathrm{m}$ on the Trivalent chromium plating on the alloy. Figure 10 shows the load depth profile for $5 \mathrm{~kg}$ force applied on the same alloy but with provision for electroless nickel undercoat below the duplex nickel. The indentation depth on the Hexavalent chromium variant increased to $35 \mu \mathrm{m}$ while the trivalent variant increased to $50 \mu \mathrm{m}$. This is expected as the electroless nickel undercoat has further extended the distance from the surface of the plate to the substrate. At a $10 \mathrm{~kg}$ applied force (Figure 11), indentation depth increased to $48 \mu \mathrm{m}$ for the Hexavalent compared to $80 \mu \mathrm{m}$ for the trivalent equivalent.

Table 3 shows maximum indentation and final depth at different applied loads.

- The values for indentation depth achieved in all cases show that the indenter penetrated the substrate

- Indentation increased with load applied on the material

- Indentation depth was much higher for Aluminium 6061 compared with Aluminium 1050

- In all cases the depth after removal of indentation is lower than the original depth recorded with indentation.

In most cases, indentation depth is much higher with electroless undercoat plated below the chromium compared to the same alloy without an electroless undercoat.

Table 3 also shows Vicker hardness values calculated for the various alloys under specific loads. The hardness values are found to decrease with increasing load and in most cases hardness values were higher for Aluminium 6061 compared to Aluminium 1050. Hardness values also appeared to decrease in variants with electroless nickel undercoat compared to those without nickel undercoat. 


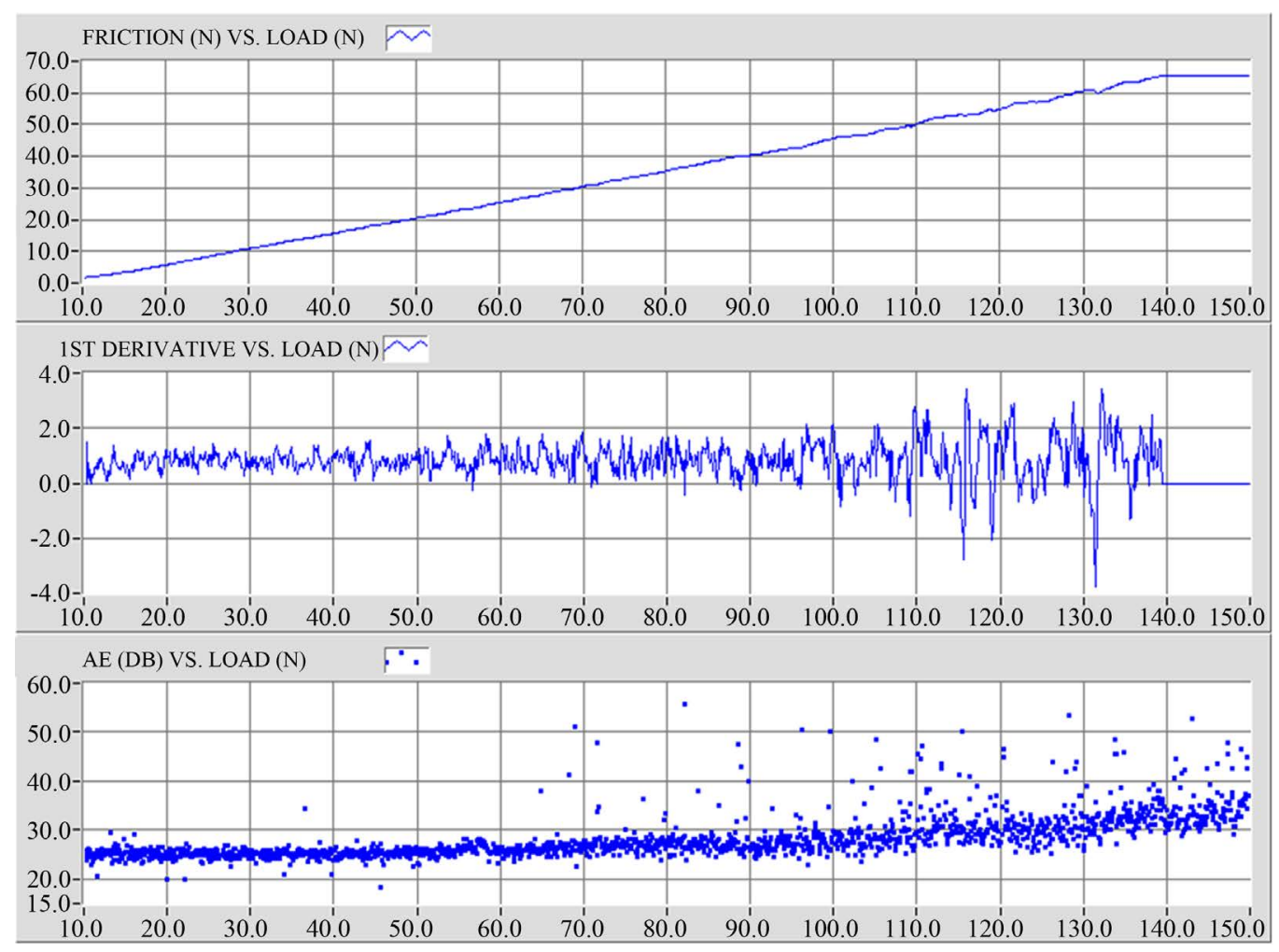

(a)

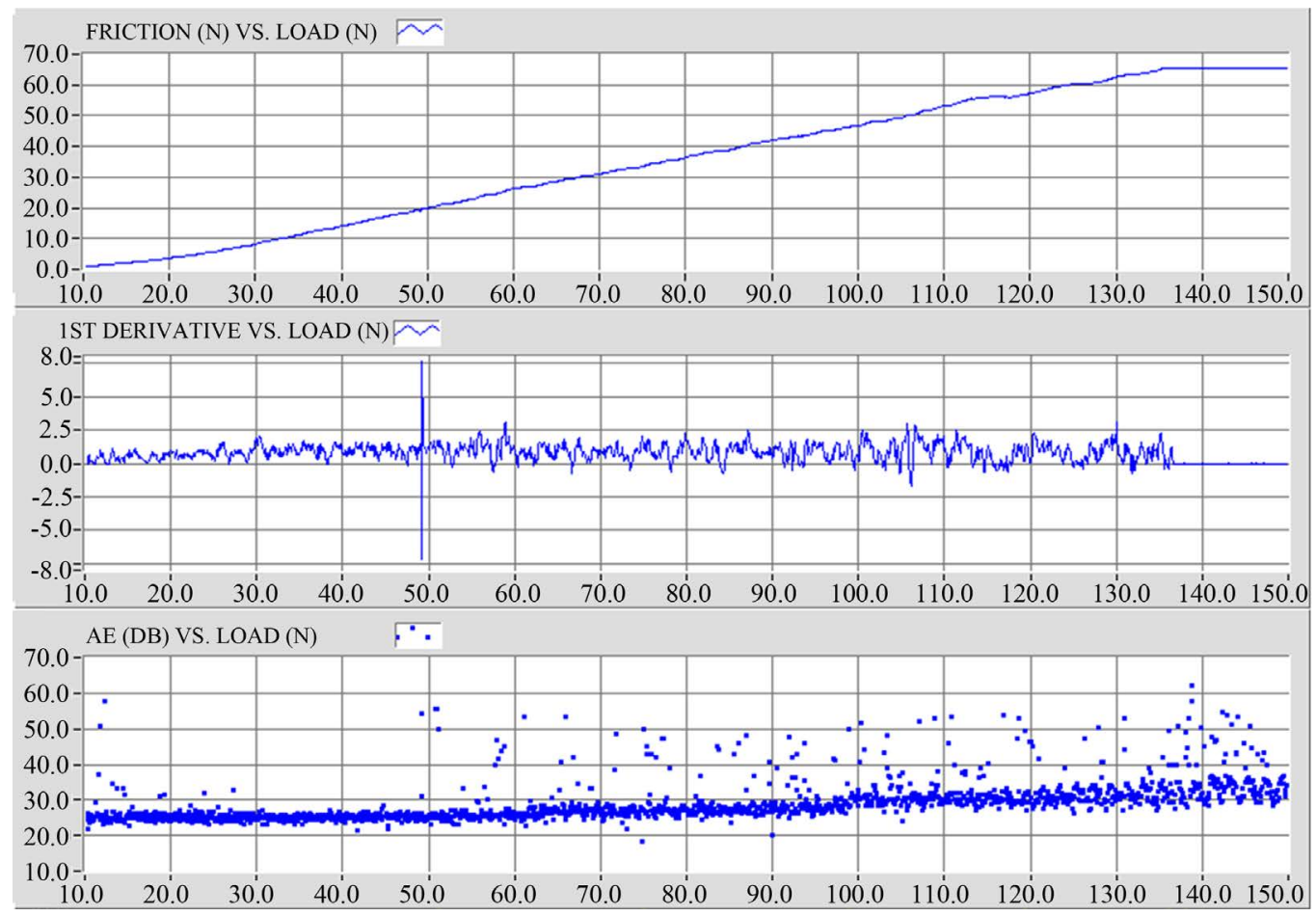

(b)

Figure 8. (a) Plot of scratch test showing friction force, first derivative of friction test and acoustic emission for duplex nickel/trivalent chromium coatings coatings onto Al 1050; (b) Plot of scratch test showing friction force first derivative of friction test and acoustic emission for duplex nickel/hexavalent chromium coatings onto $\mathrm{Al} 1050$. 


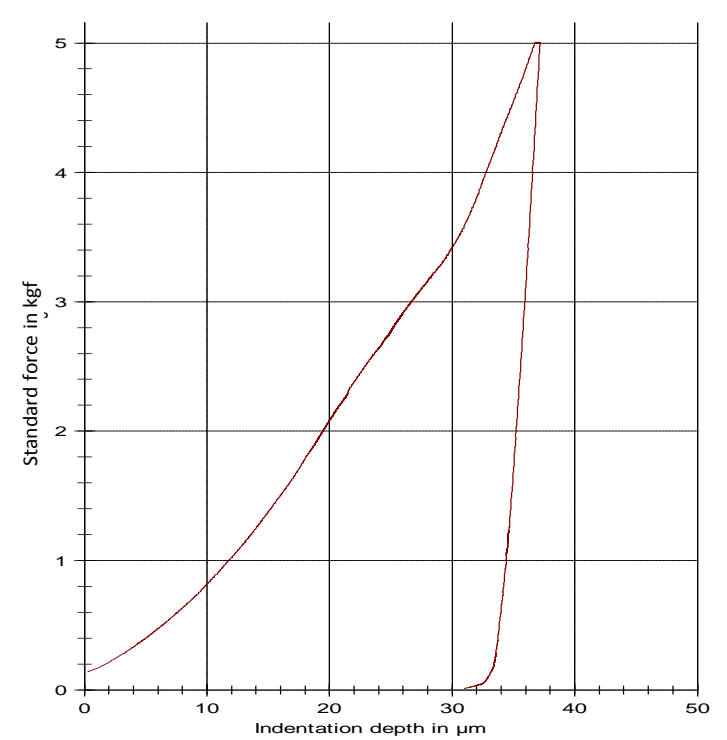

(a)

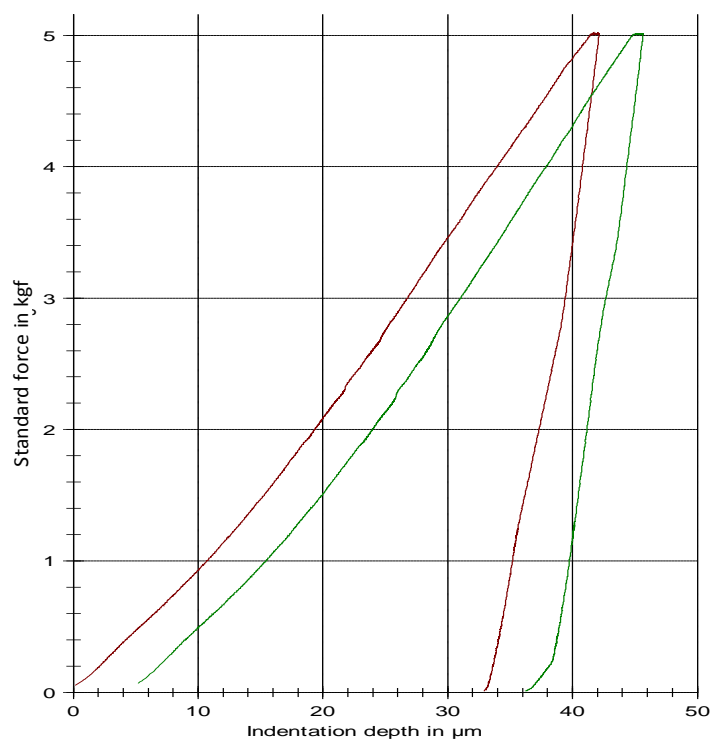

(b)

Figure 9. (a) Load-depth profile for $5 \mathrm{~kg}$ force applied duplex nickel hexavalent chromium (Al 6061); (b) Loaddepth profile for $5 \mathrm{~kg}$ force applied on duplex nickel trivalent chromium (Al 6061).

Table 2. First and second critical load values obtained from the scratch adhesion test onto $\mathrm{Al} 1050$ and $\mathrm{Al} 6061$.

\begin{tabular}{ccc}
\hline Type of chromium coatings onto aluminium substrates & First critical load (N) & Second critical load (N) \\
\hline Duplex nickel/Hexavalent chromium onto Al 1050 & 70 & 130 \\
Duplex nickel/Trivalent chromium onto Al 1050 & 85 & 135 \\
Duplex nickel/Hexavalent chromium onto Al 6061 & 22 & 72 \\
Duplex nickel/Trivalent chromium onto Al 6061 & 25 & 70 \\
\hline
\end{tabular}

Table 3. Vicker hardness measurement for variant chromium coatings.

\begin{tabular}{|c|c|c|c|}
\hline \multirow[b]{2}{*}{ Sample Variant } & \multicolumn{3}{|c|}{ Al 1050 at a load of $5 \mathrm{~kg}$} \\
\hline & $\begin{array}{l}\text { Depth of indentation } \\
(\boldsymbol{( \mu \mathrm { m } )}\end{array}$ & $\begin{array}{l}\text { Depth after removal } \\
\qquad(\boldsymbol{\mu m})\end{array}$ & $\begin{array}{l}\text { Vicker Hardness } \\
\left(\mathbf{N} / \mathbf{m m}^{2}\right)\end{array}$ \\
\hline Duplex nickel + Hexavalent chromium & 42 & 32 & 5255.102 \\
\hline $\begin{array}{l}\text { Duplex nickel + Hexavalent chromium + } \\
\text { electroless nickel undercoat }\end{array}$ & 55 & 52 & 3064.463 \\
\hline Duplex nickel + Trivalent chromium & 52.5 & 40 & 3363.265 \\
\hline $\begin{array}{l}\text { Duplex nickel + Trivalent chromium + } \\
\text { electroless nickel undercoat }\end{array}$ & 58 & 46 & 2755.648 \\
\hline Sample Variant & \multicolumn{2}{|c|}{ Al 6061 at a load of $5 \mathrm{~kg}$} & Vicker Hardness $\left(\mathbf{N} / \mathbf{m m}^{2}\right)$ \\
\hline Duplex nickel + Hexavalent chromium & 38 & 32 & 6419.668 \\
\hline $\begin{array}{l}\text { Duplex nickel + Hexavalent chromium + } \\
\text { electroless nickel undercoat }\end{array}$ & 48 & 36 & 4023.438 \\
\hline Duplex nickel + Trivalent chromium & 39 & 33 & 6094.675 \\
\hline $\begin{array}{l}\text { Duplex nickel + Trivalent chroium + } \\
\text { electroless nickel undercoat }\end{array}$ & 58 & 52 & 2755.648 \\
\hline
\end{tabular}




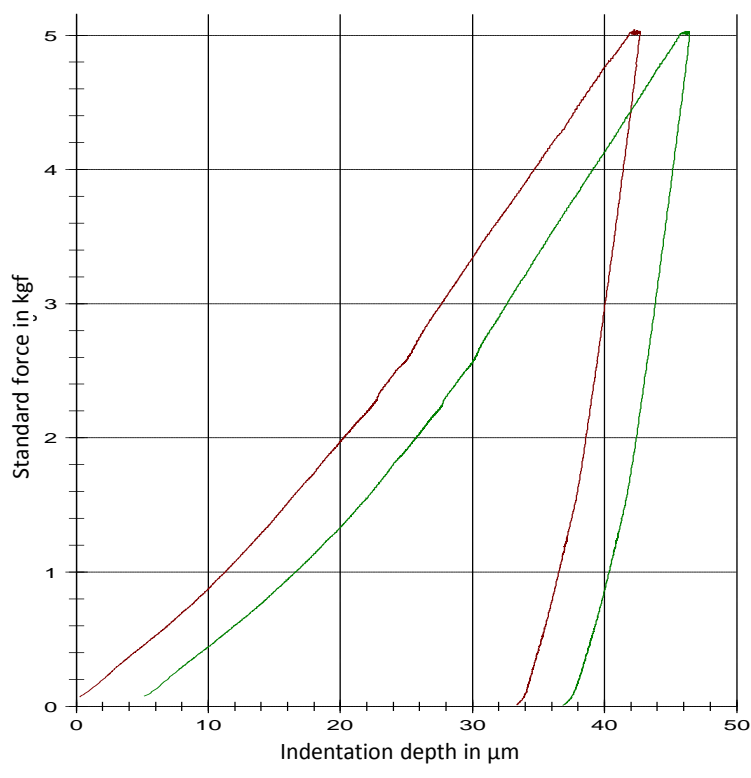

(a)

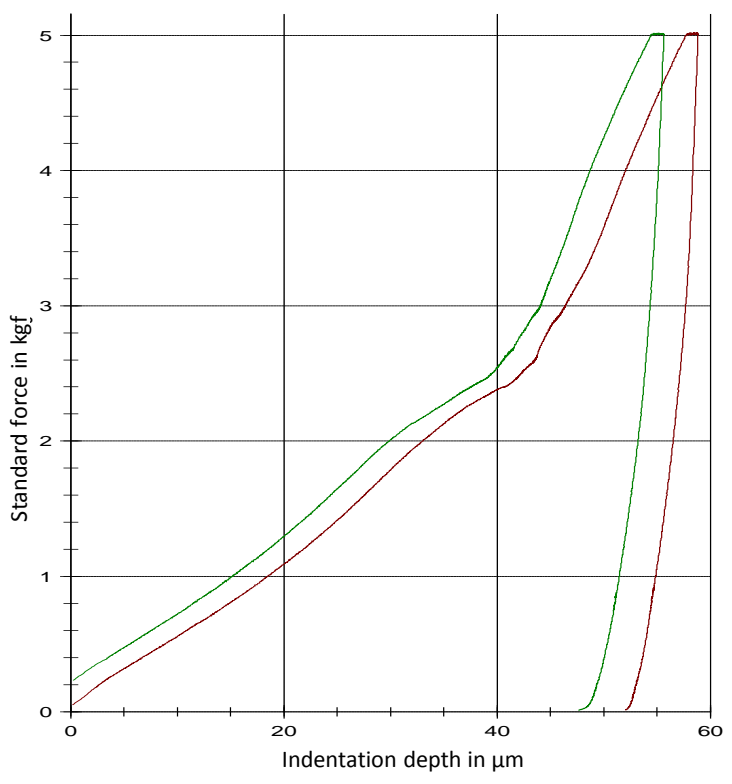

(b)

Figure 10. (a) Load-depth profile for 5 kg force applied on duplex nickel hexavalent chromium (Al 6061) with electroless nickel undercoat; (b) Load-depth profile for $5 \mathrm{~kg}$ force applied on duplex nickel trivalent chromium (Al 6061) with electroless nickel undercoat.

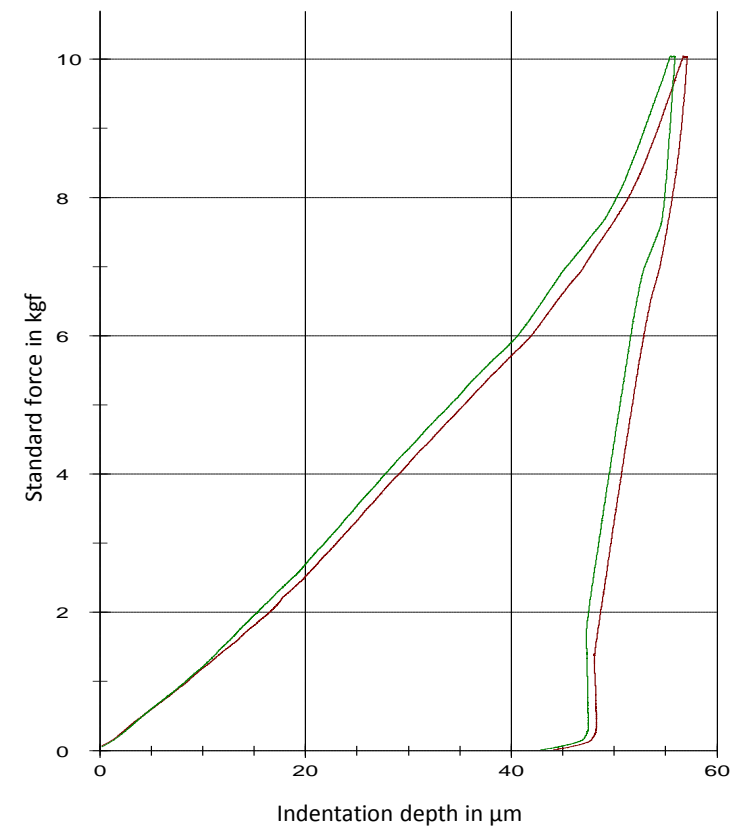

(a)

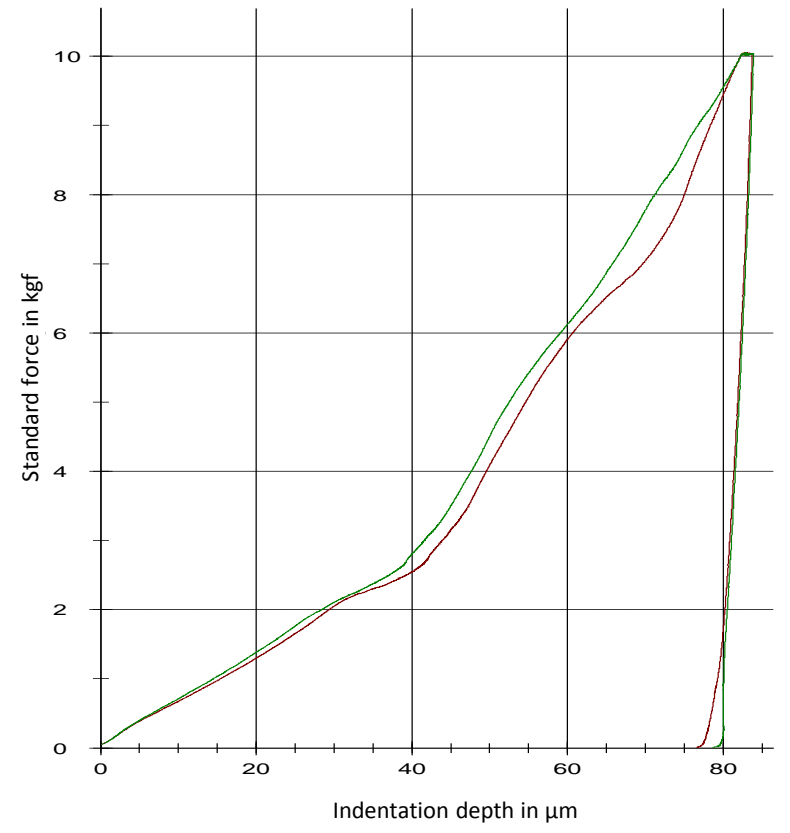

(b)

Figure 11. (a) Load-depth profile for $10 \mathrm{~kg}$ force applied on Duplex nickel hexavalent chromium (Al 6061); (b) Load-depth profile for $10 \mathrm{~kg}$ force applied on Duplex nickel trivalent chromium (Al 6061).

\subsection{Copper Accelerated Acetic Acid Salt Spray Testing of Variant Chromium Coatings}

Corrosion testing of chromium plated Al 1050 and Al 6061 samples was carried out using copper accelerated acetic acid salt spray test (CASS). Figure 12 shows photographs of chromium plated samples after 24 hours and 96 hours in the CASS test chamber. There is evidence of intense corrosion (white powder) especially after 96 hours in the test chamber. 


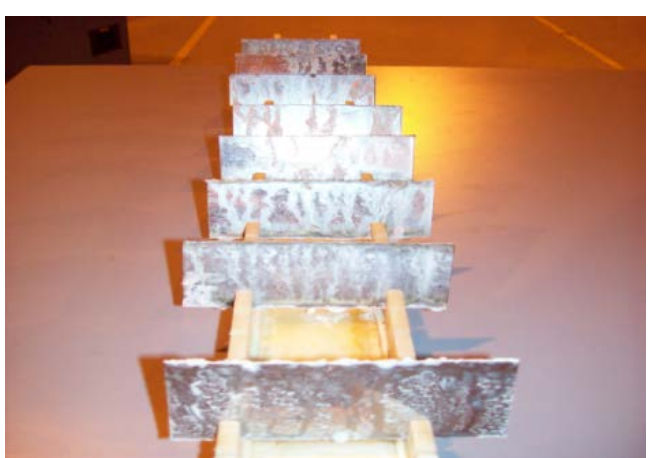

(a)

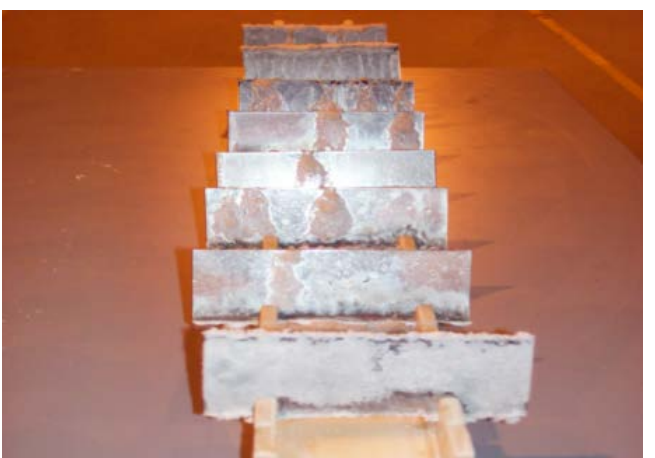

(b)

Figure 12. Chromium plated samples photographed after (a) 24 Hours and (b) 96 hours in a CASS testing chamber.

\subsection{Evaluation of Chromium Plated Aluminium Alloys after CASS Test Using Scanning Electron Microscope}

Figure 13(a) to Figure 13(d) show scanning electron micrographs of cross sections of chromium plated alloy samples after 24 and 96 hours of copper accelerated acetic acid salt spray test. The results of the CASS test demonstrate the durability of the chromium coatings acting as protective layer for the substrate. The results show the level of corrosion resistance associated with the nickel/chromium coatings on both alloy samples, with and without electroless nickel deposition as undercoat.

Overall, the micrographs show some pits and pores and evidence of preferential attack on the bright nickel directly underneath the microporous chromium coatings. The pores due to corrosion appear to have penetrated more into the bright nickel layer showing a well-defined pit shape, but however, have not spread into the semi-bright nickel layer. While there is evidence of initiation and propagation of small pits beneath the chromium, these did not appear to coalesce to form large and deep craters that could result in the eventual failure of the coatings. Defects from corrosion tend to spread laterally forming cup shaped pits which are not significant and therefore are unable to form deep craters into the coatings. Both hexavalent and trivalent chromium deposit surfaces showed similar responses to the CASS test, however, the pit sizes in the case of trivalent chromium deposition were comparatively bigger.

Overall, there seem to be no visible difference in morphology between alloy variants with and without electroless nickel undercoat following the CASS test, however, electroless deposition provides an additional layer directly below the duplex nickel layer which further protects the substrate from early deterioration.

\subsection{Evaluation of Variant Chromium Coated Aluminium Alloy Samples Using Linear Polarization Corrosion Resistance Measurement}

Linear polarization corrosion resistance analysis was carried out to determine the corrosion current density for chromium plated $\mathrm{Al} 1050$ and $\mathrm{Al} 6061$ samples at the open circuit potential. Table 4 shows a comparison of Icorr values for variant chromium coatings (duplex nickel/trivalent and duplex nickel hexavalent) for samples measured at $30 \mathrm{~min}$ and 60 min equilibration times. Overall, Icorr values are found to increase with polarization time (compare Icorr after 30 min with $60 \mathrm{~min}$ ) for both hexavalent and trivalent chromium variants, and also with and without electroless nickel undercoat. Data acquired for Al 1050 after 30 min and 60 min equilibration times were found to be much higher than those for $\mathrm{Al} \mathrm{6061.} \mathrm{This} \mathrm{implies} \mathrm{that} \mathrm{Al} 6061$ was more corrosion resistant than Al 1050. Icorr data for trivalent chromium coatings including variants with electroless nickel undercoat were much higher than those for hexavalent chromium which shows that the hexavalent chromium had a lower rate of corrosion compared to the trivalent equivalent.

\section{Conclusions}

The study carried out here has described the development of a methodology for duplex nickel chromium electroplating of aluminium alloys with the option of electroless nickel plated as under layer to the chromium. The study has produced the following conclusions: 


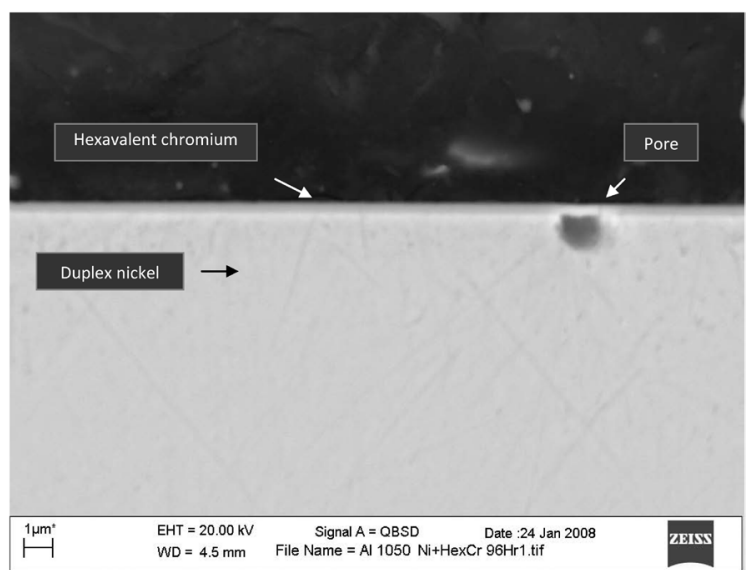

(a)

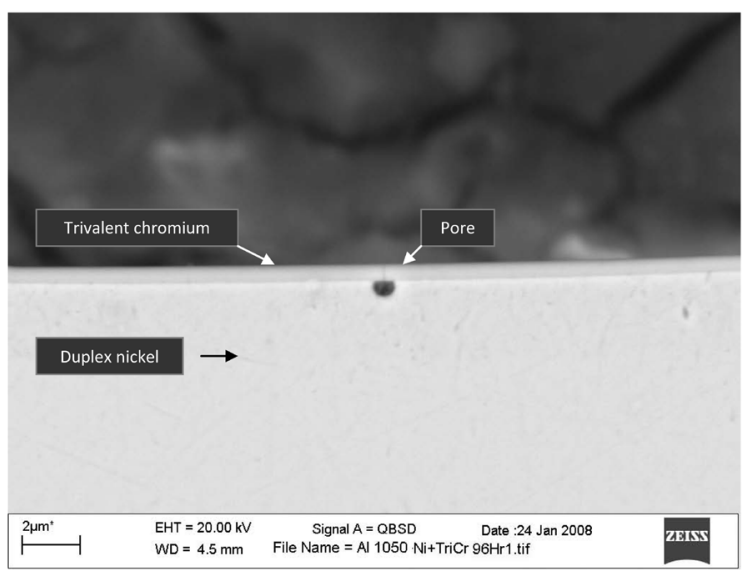

(c)

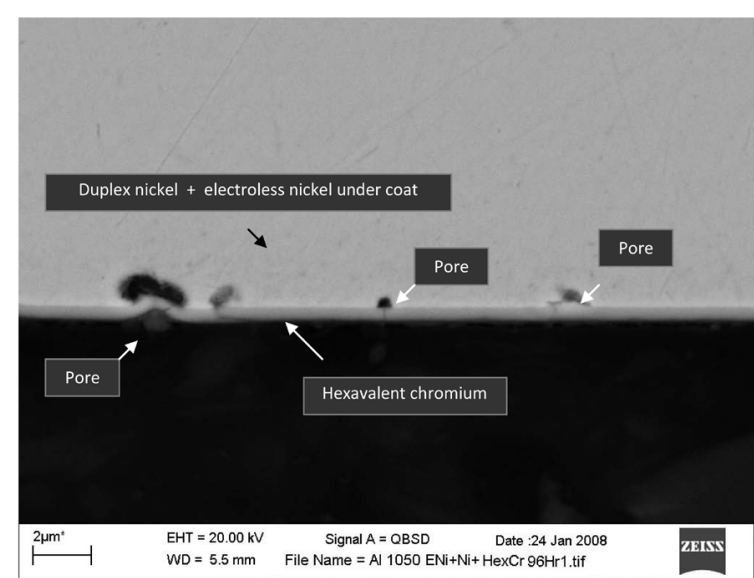

(b)

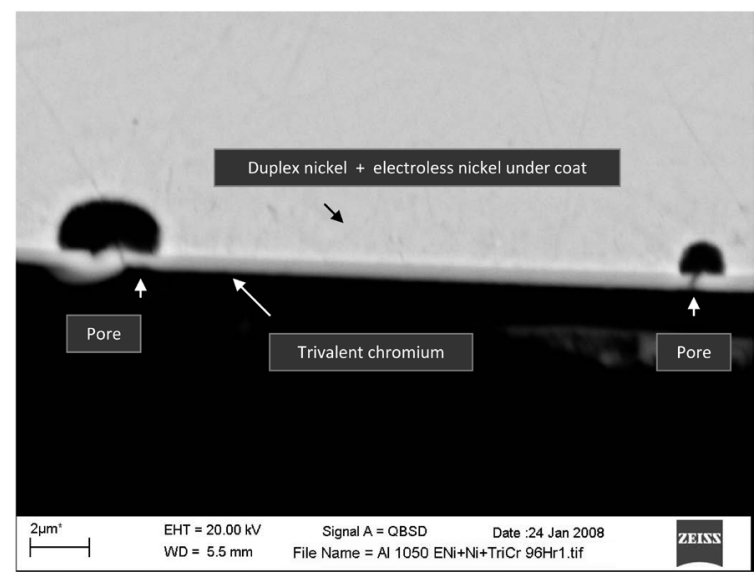

(d)

Figure 13. (a) Cross sectional SEM micrographs of CASS test after 96 hours for duplex nickel/hexavalent chromium deposits onto Al 1050; (b) Cross sectional SEM micrographs of CASS test after 96 hours for duplex nickel/hexavalent chromium deposits onto Al 1050 with electroless nickel undercoat; (c) Cross sectional SEM micrographs of CASS test after 96 hours for duplex nickel/trivalent chromium deposits onto Al 1050; (d) Cross sectional SEM micrographs of CASS test after 96 hours for duplex nickel/trivalent chromium deposits onto $\mathrm{Al} 1050$ with electroless nickel undercoat.

Table 4. Icorr values as a measure of linear polarization corrosion resistance for variant chromium coatings on $\mathrm{Al} 1050$ and Al 6061.

\section{Al 1050}

Duplex nickel + Hexavalent chromium

Electroless nickel + Duplex nickel + Hexavalent chromium

Duplex nickel + Trivalent chromium

Electroless nickel + Duplex nickel + Trivalent chromium

Al 6061

Duplex nickel + Hexavalent chromium

Electroless nickel + Duplex nickel + Hexavalent chromium

Duplex nickel + Trivalent chromium

Electroless nickel + Duplex nickel + Trivalent chromium
I corr values (nanoamp/cm²) for $30 \mathrm{~min}$ I corr values (nanoamp/ $\mathrm{cm}^{2}$ ) for $60 \mathrm{~min}$

$\begin{array}{ll}81.5 & 175.8 \\ 329.0 & 437.5 \\ 540.1 & 576.5 \\ 595.8 & 635.7\end{array}$

I corr values (nanoamp/ $\mathrm{cm}^{2}$ ) for $30 \mathrm{~min}$ I corr values (nanoamp/ $\mathrm{cm}^{2}$ ) for $60 \mathrm{~min}$

$\begin{array}{ll}18.34 & 75.21 \\ 43.97 & 82.38 \\ 23.56 & 57.42 \\ 112.6 & 279.5\end{array}$


- Atomic force microscopy images for duplex nickel/hexavalent chromium and duplex nickel/trivalent chromium coatings on aluminium 1050 showed evidence of microcracks. However, this was more prominent on the hexavalent variant. The average and root mean square roughness data showed that both hexavalent and trivalent chromium coatings portrayed relatively smooth surfaces for both alloys. However, average surface roughness values for duplex nickel/hexavalent chromium and duplex nickel/trivalent chromium coatings were comparatively higher for $\mathrm{Al} 1050$ than for $\mathrm{Al} \mathrm{6061.} \mathrm{There} \mathrm{appeared} \mathrm{to} \mathrm{be} \mathrm{a} \mathrm{marginal} \mathrm{surface} \mathrm{roughness}$ improvement with electroless nickel underlayer, compared to the variants without an underlayer.

- SEM cross-sectional micrographs showed that the chromium layer was not affected even after 96 hours of CASS testing for both hexavalent and trivalent chromium coatings on the two alloy samples. However, tiny pits and pores were observed penetrating the bright nickel layer but only spreading laterally. There was no perceptible difference noticed between trivalent chromium platings compared to the hexavalent equivalent to draw a conclusion. However, linear polarization data confirm higher corrosion rate for the trivalent compared to the hexavalent plating. The small pits and pores did not coalesce to form large and deep craters which could generate coating failure. It could therefore be concluded that chromium coatings on both aluminium samples offered good resistance to corrosion with an electroless nickel under layer further shielding the substrate from exposure to early corrosion.

- The failure mode in the scratch adhesion test started with buckling which then continued with chipping across the scratch channel. However, the surfaces observed under SEM showed that there were no signs of spallation and delamination of the coatings and confirmed that chromium coating was sufficiently adherent to the substrate. The alloy samples with electroless nickel undercoat appeared indifferently during scratch testing and therefore they were ignored as part of the results. The adherence characteristics exhibited by $\mathrm{Al}$ 1050 at both first and second critical loads were higher than those for $\mathrm{Al} 6061$.

- In most cases for Vickers hardness testing, hexavalent chromium showed higher hardness values compared to trivalent chromium plating. The average hardness values confirmed that both hexavalent and trivalent chromium coatings all decreased in hardness with electroless nickel undercoat.

- The Icorr data (reflecting linear polarization corrosion resistance) obtained from electrochemical linear polarisation for both alloy samples appeared to increase with electroless nickel undercoat. Icorr values for trivalent coating were also higher than those for the hexavalent equivalent showing that the trivalent equivalent had a higher rate of corrosion. Similarly, Al 1050 showed a higher corrosion rate than Al 6061.

\section{Acknowledgements}

We wish to express our gratitude to the Engineering and Physical Sciences Research Council, UK for the sponsorship of this project and to MacDermid Plc for providing some of the materials and equipment used in this study.

\section{References}

[1] Funatani, K. (2000) Emerging Technology in Modification of Light Metals. Journal of Surface and Coating Technology, 133-144, 264-272

[2] Carle, D. and Blount, G. (1999) The Suitability of Aluminium as an Alternative Material for Car Bodies. Journal of Materials and Design, 20, 267-272. http://dx.doi.org/10.1016/S0261-3069(99)00003-5

[3] Wernick, S., Pinner, R. and Sheasby, P.G. (1987) The Surface Treatment and Finishing of Aluminium and Its Alloys. 5th Edition, Vol. 1-2, Finishing Publications Limited, Teddington, 1-1083.

[4] Khan, M.E., Farr, J.P.G., Pearson, T. and Oduoza, C.F. (2004) Pretreatment of Aluminium Alloys for Sustainable Electroplating-A Preliminary Study. European Symposium on Electrochemical Engineering, Toulouse, 3-5 October 2005, 505-510.

[5] Dennis, J. K. and Such, T.E. (1993) 3rd Edition, Woodhead Publishing Limited, Cambridge, 206-344.

[6] Takacs, D., ziraki, L.S., Torok, T.I., Solyom, J., Gacsi, Z. and Gal-Solymos, K. (2007) Effects of Pre-Treatments on the Corrosion Properties of Electroless Ni-P Layers Deposited on AlMg2 Alloy, Surface \&Coatings Technology, 201, 4526-4535. http://dx.doi.org/10.1016/j.surfcoat.2006.09.045

[7] Hino, M., Murakami, K., Mitooka, Y., Muraoka, K. and Kamdani, T. (2009) The Effects of Zincate Treatment on Adhesion of Electroless Ni-P Coating onto Various Aluminium Alloys. Transactions of Nonferrous Metals Society of China, 19, 814-818. http://dx.doi.org/10.1016/S1003-6326(08)60356-8 
[8] Voorwald, H.J.C., Padilha, R., Costa, M.Y.P., Pigatin, W.L. and Cioffi, M.O.H. (2007) Effect of Electroless Nickel Interlayer on the Fatigue Strength of Chromium Electroplated AISI 4340 Steel. International Journal of Fatigue, 29, 695-704. http://dx.doi.org/10.1016/j.ijfatigue.2006.07.004

[9] Abdel Hamid, Z. and Abou Elkhair, M.T. (2002) Development of Electroless Nickel-Phosphorus Composite Deposits for Wear Resistance of 6061 Aluminium Alloy. Material Letters, 57, 720-726. http://dx.doi.org/10.1016/S0167-577X(02)00860-1

[10] Wu, L.-P., Zhao, J.-J., Xie, Y.-P. and Yang, Z.D. (2010) Progress of Electroplating and Electroless Plating on Magnesium Alloy. Transactions of Nonferrous Metals Society of China, 20, 630-637. http://dx.doi.org/10.1016/S1003-6326(10)60552-3

[11] Khan, M.E., Oduoza, C.F. and Laoui, T. (2005) Conference Electrochem. Newcastle-Upon-Tyne, UK.

[12] Baral, A. and Engelken, R.D. (2002) Chromium-Based Regulations and Greening in Metal Finishing Industries in the USA. Environmetal Science Policy, 5, 121-133.

[13] Khan, M.E. (2009) Investigation of Electroless Nickel Undercoat for Duplex Nickel Chromium Electrodeposition onto Aluminium Alloys. MPhil Thesis, University of Wolverhampton, Wolverhampton.

[14] Aluminium Federation (2003) Birmingham, UK.

[15] MacDermid plc (2000) Bondal Process Technical Data Sheet, Birmingham, UK.

[16] MacDermid plc (2000) Minco Cleaner, Technical Data Sheet, Birmingham, UK.

[17] MacDermid plc (2000) 66-Microetch, Technical Data Sheet, Birmingham, UK.

[18] MacDermid plc (2000) VAND ALOY 6000, Technical Data Sheet, Birmingham, UK.

[19] MacDermid plc (2000) NiMac Technical Data Sheet, Birmingham, UK.

[20] MacDermid plc (2000) NiMac Clarion II Technical Data Sheet, Birmingham, UK.

[21] MacDermid plc (2000) NiMac Hypore XL Technical Data Sheet, Birmingham, UK.

[22] MacDermid plc (2000) Mach 2 Technical Data Sheet, Birmingham, UK.

[23] MacDermid plc (2000) Tri Mac HI Technical Data Sheet, Birmingham, UK.

[24] Meade, L.C. (2000) Accelerated Corrosion Testing. Journal of Metal Finishing, 98, 542-545.

[25] Lewis, D.B. (1992) Scanning Electron Microscopy and X-Ray Microanalysis. Transactions of Institute of Metal Finishing, 70, 198.

[26] Smith, J., Campbell, S. and Walsh, F.C. (1998) The Use of Scanning Probe Microscopy in Surface Finishing and Engineering. Transactions of the Institute of Metal Finishing, 76, B53-B61.

[27] Smith, J., Campbell, S. and Breakspear, S. (2003) Introduce AFM for Surface Finishing, Part I and II. Transactions of the Institute of Metal Finishing, 81, 35-40, 35-38.

[28] Tait, W.S. (1994) An Introduction to Electrochemical Corrosion Testing for Practising Engineers and Scientists. Chapter IV, Pair O Docs Professionals L.L.C., Madison, 43-51.

[29] Mansfeld, F. (2003) Electrochemical Methods of Corrosion Testing. ASM Handbook, Volume 13A, Corrosion: Fundamentals, Testing and Protection, Association of Corrosion Engineers, 446-462.

[30] Stallard, J., Teer, D.G. and Poulat, S. (2006) The Study of Adhesion of TiN Coating on Steel and Titanium Alloy Substrate Using a Multi Mode Scratch Tester. Tribology International, 39, 159-166. http://dx.doi.org/10.1016/j.triboint.2005.04.011

[31] Snyder, D.L. (2000) Decorative Chromium Plating. Metal Finishing, 98, 215-222. http://dx.doi.org/10.1016/S0026-0576(00)80328-1

[32] Bull, S.J. and Berasetgu, E.G. (2006) An Overview of the Potential of Quantitative Coating Adhesion Measurement by Scratch Testing. Tribology International, 39, 99-114. http://dx.doi.org/10.1016/j.triboint.2005.04.013

[33] Chandler, H. (1999) Hardness Testing. 2nd Edition, the American Society of Testing and Materials, West Conshohocken, 1999.

[34] Dyrda, K. and Sayer, M. (1999) Critical Loads and Effective Frictional Force Measurements in the Industrial Scratch Testing of TiN on M2 Tool Steels. Thin Solid Films, 355-356, 277-283. http://dx.doi.org/10.1016/S0040-6090(99)00450-2. 
Scientific Research Publishing (SCIRP) is one of the largest Open Access journal publishers. It is currently publishing more than 200 open access, online, peer-reviewed journals covering a wide range of academic disciplines. SCIRP serves the worldwide academic communities and contributes to the progress and application of science with its publication.

Other selected journals from SCIRP are listed as below. Submit your manuscript to us via either submit@scirp.org or Online Submission Portal.
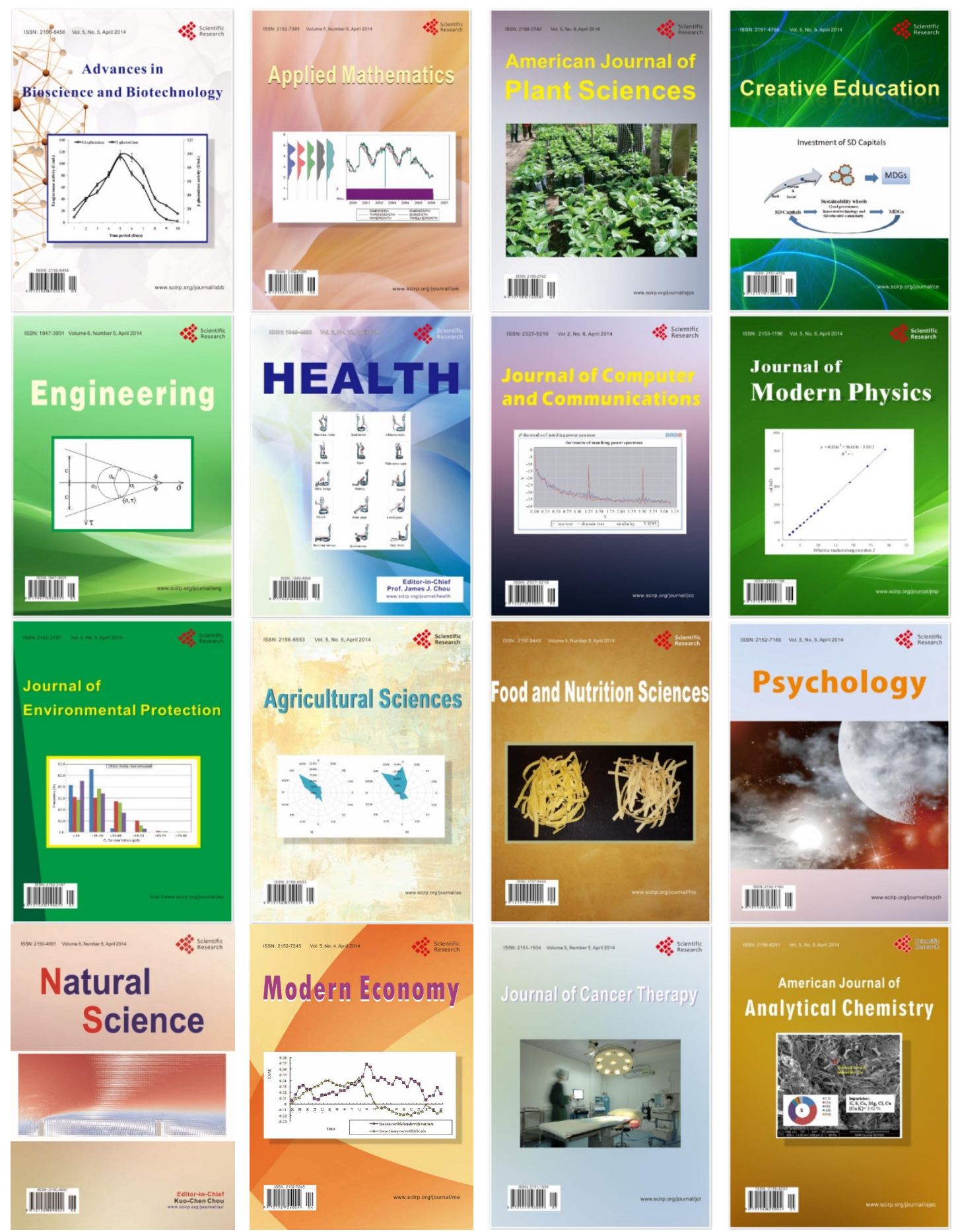